\title{
Memória e Espaço Escolar: os 100 anos da escola Maria Quitéria
}

\author{
Rebeca Laíse Santos Lima ${ }^{1}$; Ione Celeste de Jesus Sousa²; \\ 1. Bolsista PROBIC, Graduando em História, Universidade Estadual de Feira de Santana, e-mail: \\ rebecalaise@gmail.br \\ 2. Orientador, DFCH, Universidade Estadual de Feira de Santana, e-mail: \\ ionecjs@gmail.br
}

PALAVRAS-CHAVE: Memoria; Espaço Escolar Feira de Santana

\section{INTRODUÇÃO}

O projeto tem por objetivo analisar a construção da memória da Escola Maria Quitéria, através do olhar e das memórias de suas ex- alunas e pretende também acompanhar o espaço escolar como lugar e território onde os indivíduos interagem de forma individual e coletivo possibilitando o diálogo entre os ambientes interno e externo. Esta pesquisa é continuação de minhas pesquisas desenvolvidas sobre o processo de escolarização em Feira de Santana e Arquitetura Escolar durante o período de 1910 a 1940. O foco da pesquisa nesta escola se deve aos seus cem anos de funcionamento no de 2017, com poucas alterações na sua estrutura principal, além de ter formado alunos e alunas que fizeram e fazem parte da sociedade feirense. Nesse sentido a escola se insere no processo de construção da memória escolar feirense onde o espaço escolar se configura como elemento chave na investigação da cultura escolar de uma determinada Instituição Escolar. O espaço escolar tem se constituído nos últimos anos na história da educação como uma vertente promissora na pesquisa sobre cultura escolar.

\section{MATERIAL E MÉTODOS OU METODOLOGIA (ou equivalente)}

Analise das entrevistas com as ex - alunas da escola, assim como nas fontes constituídas pelos periódicos feirenses, as marcas da arquitetura escolar A perspectiva é da História Cultural que toma as construções físicas como aspectos da Cultura Material e das representações dos sujeitos. Neste caso especifico a História Cultural utilizando o conceito de Cultura Escolar, como a construção de materiais e métodos de escolarização, entre estes os próprios prédios construídos a partir de noções de higiene escolar e métodos de ensino. $\mathrm{Na}$ Bolsa de IC anterior, que se encerra em Julho deste ano eu realizei leituras e fiz investigações sobre o processo de escolarização da Escola Maria Quitéria durante o período de intendência do Coronel Agostinho Froes da Mota assim como iniciei os contatos com as ex alunas. Na Bolsa de IC de 2015 cujo titulo é Arquitetura Escolar na Cidade de Feira de Santana 1910 a 1940 realizei o levantamento inicial da planta da escola Maria Quitéria.

\section{.RESULTADOS E/OU DISCUSSÃO (ou Análise e discussão dos resultados)}

Para a realização do trabalho foram utilizadas entrevistas com as ex-alunas onde estas relatam a sua trajetória na escola, o bairro onde viviam, e as memórias que possuem da escola, além disso houve também visitas ao espaço escolar para observar o espaço escolar e as interações entre os alunos e seu entorno e conversas com funcionários. $\mathrm{O}$ texto de Ferreira, é importante para esta pesquisa pois discute os conceitos de história e 
memória e a importância da história oral para a construção da memória conceito foco deste trabalho. A obra está estruturado em três tópicos seguido pela conclusão. A historiadora tem por objetivo discutir ao longo do texto os problemas teóricos e metodológicos da história e para isso ela vai percorrendo o caminho da história na sua constituição enquanto ciência e suas diversas fases até os dias de hoje "discutindo a relação entre passado e presente na história e os novos caminhos para o estudo da história do século XX" p.331. De acordo com Ferreira ainda na página 331 fica claro a sua proposta, no trecho:

"Estabelecendo a diferença entre história e memória (e entre históriador e history maker), este trabalho trata dos problemas teóricos e metodológicos da história oral hoje.(p.331). Logo na introdução a autora apresenta uma breve comentário sobre a penetração da história oral e como se deu a sua incorporação como disciplina.

A sua justificava para escrever este texto consiste em entender o porquê da história oral é vista com suspeita pela comunidade de historiadores e muitas vezes ela é avaliada de forma negativa, portanto a historiadora discute aqui o porquê dessa situação e enfatiza:

"Para fazê-lo, nada melhor que lançar o olhar sobre a historiografia sobre a historiografia e observar como a história recente e as fontes e as fontes orais foram encaradas por diferentes concepções da história, e o que levou, em cada caso, a desconfiança e a desqualificação de ambas pelos historiadores" p.314

A relevância do estudo dessa escola se deve a importância da construção da memória local já que esteve em atividade ao longo de um século. Localizada na Praça Agostinho Froes da Mota sem número, antiga rua dos remédios e é mantida pelo governo do estado sob a direção de Ana Carla Coutinho Leite. Explicitamente sobre esta cidade e sua memória, Ione Sousa (2012) afirma sobre a presença da Escola Normal de Feira de Santana:

"Além do estritamente relativo a vida cotidiana intraportões da Escola Normal, apresento seus entrelaçamentos com a modernização urbana da cidade de Feira de Santana, nos anos 1920/40, com a abertura de novas ruas e avenidas, que alimentou a emergência de novas sociabilidades públicas para as normalistas e outras moças de escola, a exemplo dos passeios pela rua Conselheiro Franco e próximas" (SOUSA, 2012, p.125).

O prédio da escola Maria Quitéria se localiza na mesma praça do palacete Froes da Motta, residência do Coronel Agostinho que se tornou na época ponto de referência para os mais diversos eventos da cidade e sediou reuniões políticos. $\mathrm{O}$ palacete tem uma arquitetura requintada e possui um estilo eclético, que mistura traços de dois outros estilos arquitetônicos do período, e serviu de instrumento para ostentar o poder, a imponência e o prestigio da sua família. Em sua pesquisa, Oliveira especifica a escolarização empreendida pelo Coronel Agostinho, ela desconstrói o mito de que sua motivação vinha da sua origem humilde, trazendo evidências dos interesses políticos e econômicos de Agostinho. A construção desses palacetes educacionais suntuosos, que possuíam como característica uma arquitetura sofisticada se contrapondo as antigas 
escolas que funcionavam em casas onde os professores residiam e que se encontravam isoladas, serviam para evidenciar o progresso de uma modernidade através da mudança na concepção e organização escolar, segundo Faria Filho. Como já foi salientada a escola Maria Quitéria continua funcionando normalmente no mesmo local e seu prédio sofreu poucas intervenções arquitetônicas ao longo dos seus anos de funcionamento, o prédio foi tombado como patrimônio histórico de Feira de Santana. A escolha do nome é uma homenagem a heroína feirense Maria Quitéria de Jesus Medeiros, que se disfarçou de homem, sendo a primeira mulher a entrar nas forças armadas, usurpando e infringido as regras que proibia as presença de mulheres no exército, lutou nas lutas pela independência da Bahia em 1823, o prédio só recebeu essa denominação em 1930, até 1928 funcionou apenas com o nome de prédio escolar e em 1928 recebeu o modelo de Escolas Reunidas para meninos em Feira de Santana, recebendo em 1930 a denominação de Escola Maria Quitéria que perdura até os dias atuais. De acordo com Oliveira a construção destes prédios escolares serviram para abrigar três escolas isoladas elementares municipais, se adequando dessa forma ao projeto político civilizatório republicano, pois estas escolas isoladas se localizam em casas alugadas distantes do centro comercial e era local das aulas e a residência do professor. Sobre a escola Maria Quitéria que é o foco desta investigação, em Feira de Santana, Oliveira (2011) em monografia de graduação, informa que seu primeiro professor municipal nomeado foi Geminiano Alves da Costa, em 1919, antigo professor feirense, atuante tanto nas aulas públicas municipais, como nas aulas para pobres ofertadas na Irmandade de São Benedito desta cidade. As questões arquitetônicas e o processo de escolarização da Maria Quitéria foi alvo da pesquisa de Iniciação Cientifica onde iniciei os primeiros contatos com ex - alunas da escola que estudaram no início da década de 40. Duas das ex-alunas que seriam entrevistadas faleceram após os primeiros contatos dificultando a realização das atividades, mas objetivo proposto pode ser alcançado já que uma das exalunas continua viva e atuante no cenário sociocultural de Feira de Santana, e além disso foram feitas também entrevistas com ex-alunas de uma década mais recente, sendo que uma delas voltou na escola e atuou como professora de história. No entanto nas suas falas nos primeiros contatos mantidos era evidente o saudosismo ao período em que estudaram na escola, nos revelando aspectos da dinâmica escolar e sua interação com as práticas educativas. Nas falas das alunas entrevistadas observamos a mudanças de comportamento, mas mesmo em épocas diferentes todas relataram que a escola mantém uma linha rígida em relação ao comportamentos dos alunos e ao fardamento e que a mesma mantém uma preocupação com a comunidade, mantendo um constante diálogo entre os pais dos alunos, professores, funcionários e direção através de um colegiado escolar onde cada um possui um representante. Outro fator que foi observado durante as entrevistas e nas visitas a escola é o quadro de alunos que compõe a escola são alunos de distritos e de bairros periféricos por ser um local de fácil acesso para a chegada destes. A avaliação das alunas da escola durante o período em que estudaram é de que era uma ótima escola, com bons professores e em uma das entrevistas conversei com uma das alunas que teve a oportunidade de voltar para a escola como professora de história, ela relatou sua experiência afirmando que foi importante para ela pois pode provar para os seus professores que apesar de ser uma aluna de embates e que foi suspensa e desacreditada por alguns, ela conseguiu vencer os obstáculos e mostrar a sua trajetória de luta e construção de uma identidade que permitiu ela estar ali agora como colega. A aluna da década de 40 nos forneceu detalhes do funcionamento da escola neste período que segundo ela, funcionava só para meninas e que durante o intervalo elas brincavam e cantavam e alunas tinham um temor pelo professor e não o questionavam, a palavra do professor era lei e nesse momento identificamos que a concepção pedagógica desse período era tradicional, o professor estava em sala de aula 
apenas para transmitir o conhecimento. Já nas décadas mais recentes identificamos que concepção pedagógica utilizada pela escola é a liberal renovada. Durante o levantamento de dados da bolsa anterior eu já tinha conseguido uma foto de uma das alunas com seus dois irmãos com os fardamentos da Maria Quitéria e João Florêncio e esta mesma aluna me forneceu uma foto sua com a farda da escola. As imagens obtidas da escola em sua maioria são recentes e só possuo duas fotos da escola em períodos mais antigos.

\section{CONSIDERAÇÕES FINAIS (ou Conclusão)}

A pesquisa nos permite concluir que trabalhar com a memória destes indivíduos contribui para identificarmos através dos olhares as experiências vividas e de como estas influenciam a construção da memória coletiva e de sua relevância para a memória local.

\section{REFERÊNCIAS}

1. BENCOSTA, Marcus Levy. História da Educação, Arquitetura e Espaço Escolar. SP: Cortez; 2005.

2. BENCOSTA, M. L. A. A noção da cultura material escolar em debate no campo da investigação da História da Educação. In: César Augusto Castro e Samuel Luis Velásquez Castellanos. (Org.). A Escola e seus artefatos culturais. 1 ed. São Luiz: EDUFMA, 2013, v.1, p. 21-34.

3. BENCOSTA, M. L. A. "Grupos Escolares no Brasil: um novo modelo de escola primaria”. In: STEPHANOU, M e BASTOS, M.HC. (orgs.) História e memorias da educação no Brasil. Vol. III. PETROPOLIS: Editora Vozes, 2005.

4. FARIA FILHO, L. M. de. Dos pardieiros aos palácios. Cultura Escolar e urbana em Belo Horizonte na Primeira República. Passo Fundo: Editora da UPF, 2000.

FERREIRA, M.M. HISTÓRIA, TEMPO PRESENTE E HISTÓRIA ORAL.TOPOI (Rio de JANEIRO). RIO DE JANEIRO. V 1, N. 5. P. 314 - 332, 2002.

5. OLIVEIRA, Daiane Silva. INSTRUÇÃO DE POBRES E NEGROS EM FEIRA DE SANTANA: As Escolas do Professor Primário Geminiano Alves da Costa (1890 a 1920). Feira de Santana, UEFS- PPGH-Mestrado em História, 2016. Orientação prof ${ }^{a}$ Dr $^{a}$ Ione Sousa.

6. ROCHA \& BARROS, Grupos Escolares Cultura Escolar Primaria e Escolarização da Infância no Brasil 1839 - 1917. A Educação Primária Baiana: Grupos Escolares na Penumba.

7. SOUSA, Ione \& CRUZ, Antônio Roberto (orgs). Escolas Normais da Bahia: olhares e abordagens. Feira de Santana: UEFS Editora; 2013.

8. SOUSA, Ione. Garotas tricolores, Deusas fardadas: as normalistas em Feira de Santana. SP: EDUC/PUC. 2002 